\title{
FKBP5 Polymorphism, Coping and Emotional status in Chronic Obstructive Pulmonary Disease patients undergoing Pulmonary Rehabilitation
}

Giulia Prinzi ${ }^{1}$, Carlo Tomino ${ }^{2 *}$, Alessia Santoro ${ }^{1}$, Federica Marcolongo ${ }^{1}$, Vittorio Cardaci ${ }^{3}$, Massimo Fini $^{2}$, Robertina Giacconi ${ }^{4}$, Marco Malavolta ${ }^{4}$, Mauro Provinciali ${ }^{4}$, Alberto Ricci ${ }^{5}$, Stefano Bonassi ${ }^{1,6}$ and Patrizia Russo ${ }^{1,6}$.

${ }^{1}$ Unit of Clinical and Molecular Epidemiology, IRCCS San Raffaele Pisana, Via di Val Cannuta, 247, I00166 Rome, Italy; giulia.prinzi@sanraffaele.it (G.P.); alessiasantoro92@gmail.com (A.S.);

marcolongo.federica1@gmail.com (F.M.); stefano.bonassi@sanraffaele.it

(S.B.);patrizia_russo@hotmail.it (P.R.)

${ }^{2}$ Scientific Direction, IRCCS San Raffaele Pisana, Via di Val Cannuta, 247, I-00166 Rome,

Italy;carlo.tomino@sanraffaele.it (C.T.); massimo.fini@sanraffaele.it (M.F.)

${ }^{3}$ Unit of Pulmonary Rehabilitation, IRCCS San Raffaele Pisana, Via della Pisana, 235, I-00163 Rome, Italy; vittorio.cardaci@sanraffaele.it (V.C.)

${ }^{4}$ Technology Center for Aging Research, Scientific Technological Area, IRCCS-INRCA, Via Giuseppe Birarelli, I-60121 Ancona, Italy; r.giacconi@inrca.it (R.G.);

m.malavolta@inrca.it(M.M.);m.provinciali@inrca.it (M.P.)

${ }^{5}$ Department of Clinical and Molecular Medicine, Unit of Pneumology, University of Rome "La Sapienza", Via di Grottarossa, 1035, I-00189, Rome, Italy; Alberto.Ricci@uniroma1.it (A.R.)

${ }^{6}$ Department of Human Sciences and Quality of Life Promotion, San Raffaele University, Via di Val Cannuta, 247, I-00166 Rome, Italy; stefano.bonassi@sanraffaele.it (S.B.); patrizia_russo@hotmail.it (P.R.)

*Corresponding Author

Scientific Direction, IRCCS San Raffaele Pisana

IRCCS San Raffaele Pisana, Via di Val Cannuta, 247, I-00166 Rome, Italy;

carlo.tomino@sanraffaele.it 


\section{Abstract}

Background: COPD is characterized by dyspnea, chronic cough, sputum production and extra pulmonary multimorbidity including depression, anxiety and cognitive problems. Methods: Cognitive and psychological clinical alterations/disorders; QoL/Health-related QoL; and Coping strategies were evaluated in 71 COPD patients characterized for FKBP5 gene (rs4713916). Instruments: MMSE, MoCA, ROCF, BDI-II, CES-D, SAS, SF-36, ADL, IADL, SGRQ, MRF 26, CIRS, Brief COPE. Results: Carriers of the rs4713916 polymorphisms (G:A) show better cognitive performances, higher degree of independence in the ADL and IADL, better QoL before and after rehabilitation, no presence of depressive mood and anxiety symptoms, no family history of psychiatric disorder, more ability to cope with stressors by avoiding emotions but demanding emotional support, and lesser use of anti-anxiety, anti-depressant anti-psychotic, hypnotic-sedative drugs. On the other hand, no difference was found as regards the number of comorbidities. Conclusions: Our study shows that rs4713916 is positively associated with better outcome for COPD. These results offer valuable insights into the role of FKBP5 in the complex network of mechanisms associated to clinical and behavioral features of COPD patients.. Our data may be used as initial benchmark for future clinical studies.

Keywords: Anxiety, COPD, Coping strategies, Corticosteroid, Depression, Rehabilomics, rs471396. 


\section{Introduction}

Chronic obstructive pulmonary disease (COPD) is a chronic respiratory illness characterized by reversible airways inflammation and irreversible lung tissue destruction leading to increasingly severe dyspnea, chronic cough, and sputum production [1]. Dyspnea is the cause of forced patient's inactivity or disability, thus patients stay at home long time with reduced daily activity and social relation and interaction. COPD is associated with several comorbidities more often than the general population [23] and it is considered one of the primary global causes of morbidity and mortality [4-5]. COPD is the only non-communicable disease (NCD) whose prevalence continues to increase in spite of the reduction of smoking habit [6]. Despite the availability of several therapeutic options, including longacting $\beta$-agonists (LABA), long-acting muscarinic antagonists (LAMA), and inhaled corticosteroids (ICS), often used in combination, a third of COPD patients still die of non-malignant respiratory diseases, mostly COPD itself, whereas the number of COPD patients dying of cardiovascular diseases (CVDs)is constantly decreasing (from a third to a quarter) $[1,6]$. These data put emphasis on the lack of effective treatments able to decrease the respiratory-related mortality and the need of valuable diseasemodifying interventions.

Comorbidity, or better multimorbidity, is common at any grade of COPD severity [7] and the differential diagnosis is often difficult [8]. Patients with COPD often show psychiatric comorbidities, in particular, generalized anxiety, panic disorder, and depression. These conditions are associated with poorer quality of life (QoL) [9], major decline in 6 minutes walking distance (6MWD), lower compliance to the treatment plan, more acute exacerbations with more frequent admissions to emergency hospital, and ultimately with more 30-day mortality compared with their counterparts without anxiety or depression[10]. It has been reported that patients with COPD are two-to-five times more likely to meet criteria for an anxiety or depressive disorder than the general population [11]. The prevalence of depression in COPD patients is around 24.6\% [12-13] and the prevalence of anxiety is around 9.1$28.2 \%$ [13]. On the other hand this relationship is possibly bidirectional, since persons with an anxiety or mood disorder are 1.5 times more likely to have pulmonary disease [14]. 
The National Institute for Health and Care Excellence (NICE) defines multimorbidity as the cooccurrence of two or more long term illness conditions [15-16].The NICE, on its first guideline to manage multimorbidity, encourages to identify people who would benefit from an individualized approach [16]. In general, the presence of multimorbidity no alters COPD treatment and, as suggested by the GOLD report 2019, comorbidities should be treated per usual standard regardless of the presence of COPD [1].The NICE recommends to identify those patients who may take advantage of a "multimorbidity approach" evaluating treatment burden by discussing with the patient by what means his/her health problems and how treatments affect their day-to-day life [17].

Patients with COPD, suffering from multiple pulmonary and extra-pulmonary sickness, emotional and/or social limitations, need a comprehensive, multi and interdisciplinary pulmonary rehabilitation program beyond the regular pulmonary drug treatment(s) [9]. Such a program is the most effective strategy to improve shortness of breath, health status, and exercise tolerance reducing readmissions and mortality [9]. Indeed, a comprehensive pulmonary rehabilitation (PR) highlights and trusts the central role of the patient [18]. The NIH's recent research plan on rehabilitation [19], highlights the importance to understand precision medicine approaches which are relevant to rehabilitation, and to characterize those biomarkers that may be prognostic or guide prescription for rehabilitation interventions. As a natural evolution of this scenario, the so-called "Rehabilomics" research framework, initially introduced by Wagner [20], may be applied to COPD with the final purpose to influence final outcomes joining together different areas such as modern clinical pneumology, biomarkers, genetic make-up, gender, psychological symptoms, and environmental variables [21-24].

As suggested by Wagner [20] the "Rehabilomics" is a unique and distinctive model to create a foundation for developing personalized-medicine approaches to rehabilitation. In a previous work we employed a Rehabilomics-like approach to study the complexity of COPD rehabilitation process, incorporating genetics, clinical and psychological status as well as biological factors(i.e. gender) [22].Among the aims of precision medicine there is the improvement of the diagnostic process and the choice of a specific treatment driven by genetic profile or biomarkers [25]. 
COPD is a multifactorial disease where different genes are associated to etiology and progression, as well as to therapy [26]. Genetic polymorphisms (SNPs) are associated with COPD susceptibility [27], COPD severity [27], and therapeutic response [27-29].

Recently, we observed a specific association between the polymorphism (rs4713916, G:A) of the FKBP5 gene and different endpoints of PR response in COPD patients; thus GA carriers show better performances in the 6MWT and in the lung functions when compared to GG patients. Indeed, logistic regression analysis showed that patients carrying rs4713916 GA has four times more probability to be responders than $\mathrm{GG}$ patients $(\mathrm{Cl}=0.02-1.68$, odd ratio $=0.22)[23]$. Interestingly, FKBP5 is considered a risk factor for different psychiatric disorders including depression [30].

FKBP5 is a heat shock protein $90-(\mathrm{Hsp} 90)$ associated co-chaperone encoded by the FKBP5 gene. The human gene is located on the chromosome 6 at position p21.31 consisting of 13exons and 12 introns spanning more than $150 \mathrm{~kb}$ of genomic DNA [31]. The FKBP5gene is characterized by the presence of functional glucocorticoid responsive elements (GREs) that represent an intracellular short feedback loop [32]. Recently, it has been highlighted that FKBP5 shall be considered as a scaffolding protein able to organize protein complexes rather than a (co)chaperone contributing to the folding of individual proteins [33].

In this work we further investigate the susceptibility to psychological distress and quality of life of COPD patients carriers of the rs 4713916 polymorphism (G:A), to explore the complex COPD outcomes with the final goal to design individually tailored pulmonary rehabilitation strategies.

\section{Results}

A total of 70patients, previously genotyped for rs471396 (G:A) [23], with severe COPD, stage 3-4 GOLD, are studied. Table 1 shows the socio-demographic characteristics of the patients stratified according to rs471396 genotype. 
Table 1. Socio-Demographic characteristics of the study population $(\mathrm{N}=70)$ stratified according to FKBP5 rs4713916 genotype (GG or GA).

\begin{tabular}{|c|c|c|c|}
\hline Characteristics & GG (N=57) & GA (N=13) & $p$ \\
\hline \multicolumn{4}{|l|}{ Gender } \\
\hline Male & $40.35 \%$ & $53.85 \%$ & NS \\
\hline Female & $59.65 \%$ & $46.15 \%$ & \\
\hline Age & $72.66 \pm 8.6$ & $74.76 \pm 6.4$ & NS \\
\hline Education (years) & $9.21 \pm 4.3$ & $7.0 \pm 2.3$ & NS \\
\hline \multicolumn{4}{|l|}{ Marital Status } \\
\hline Married/partner & $50 \%$ & $61.54 \%$ & \\
\hline Widower & $35.09 \%$ & $15.38 \%$ & NS \\
\hline Unmarried & $3.51 \%$ & $7.69 \%$ & \\
\hline Separated/divorce & $12.28 \%$ & $15.38 \%$ & \\
\hline \multicolumn{4}{|l|}{ Smoking Habit } \\
\hline Current smoker & $16.33 \%$ & $15.38 \%$ & \\
\hline Ex-smoker & $73.47 \%$ & $76.92 \%$ & NS \\
\hline Non-smoker & $10.20 \%$ & $7.69 \%$ & \\
\hline \multicolumn{4}{|l|}{ Living situation } \\
\hline Caregiver Presence & $73.69 \%$ & $76.92 \%$ & NS \\
\hline None & $26.32 \%$ & $23.08 \%$ & \\
\hline \multicolumn{4}{|l|}{ Current occupation } \\
\hline Employed & $18.74 \%$ & 0 & \\
\hline Housewife & $10.42 \%$ & $23.08 \%$ & NS \\
\hline Retired & $70.83 \%$ & $76.92 \%$ & \\
\hline LTOT & $33.3 \%$ & $30.77 \%$ & NS \\
\hline ICS therapy & $100 \%$ & $100 \%$ & NS \\
\hline BMI & $27.95 \pm 8.5$ & $28.83 \pm 9.5$ & NS \\
\hline \multicolumn{4}{|l|}{ CIRS } \\
\hline Severity & $1.614 \pm 0.242$ & $1.531 \pm 0.192$ & NS \\
\hline Comorbidity & $2.449 \pm 1.444$ & $2.889 \pm 1.054$ & \\
\hline \multicolumn{4}{|l|}{ Comorbidity } \\
\hline Number $x$ Patients & $3.593 \pm 1.807$ & $3.100 \pm 1.595$ & NS \\
\hline \multicolumn{4}{|l|}{ Comorbidity } \\
\hline Circulatory System Diseases & $44(77.2 \%)$ & $10(76.9 \%)$ & NS \\
\hline \multicolumn{4}{|l|}{ (ICD-9-CM 390-459) } \\
\hline Endocrine, Nutritional, & $24(42.1 \%)$ & $6(38.5 \%)$ & NS \\
\hline \multicolumn{4}{|l|}{$\begin{array}{l}\text { Metabolic, and Immunity Disorders } \\
(240-279)\end{array}$} \\
\hline $\begin{array}{l}\text { Genitourinary System Diseases } \\
\text { (580-629) }\end{array}$ & $7(12.3 \%)$ & $2(15.4 \%)$ & NS \\
\hline Neoplasms & $3(5.3 \%)$ & $1(7.7 \%)$ & NS \\
\hline
\end{tabular}

* Data are expressed as mean \pm SD or percentage.

57 patients are GG and 13 are GA. The mean age is $72.66 \pm 8.6$ for GG and $74.76 \pm 6.4$ years for $\mathrm{GA}$. All patients are under ICS therapy, and are moderately overweight [34]. No major differences are observed between the two groups for gender, age, education, smoking habits, LTOT, BMI, CIRS, Number and type of 
comorbidities. In both two groups of patients the major comorbidity is related to CVDs77.2\% (GG) vs76.9\% (GA).

The cognitive functions are evaluated by three different instruments namely: MMSE, MoCA and ROCF (Direct and delayed copy) (Table 2).

Table 2. Cognitive characteristics of the study population ( $N=70)$ stratified according to FKBP5 rs4713916 genotype (GG, GA).

\begin{tabular}{|c|c|c|c|}
\hline Characteristics & GG (N=57) & GA ( $N=13)$ & $\mathbf{P}$ \\
\hline \multicolumn{4}{|l|}{ MMSE } \\
\hline Adjusted scores & $25.81 \pm 2.37$ & $26.32 \pm 3.36$ & NS \\
\hline \multicolumn{4}{|l|}{ Score range } \\
\hline 30 & 0 & 0 & \\
\hline $23.9-30$ & $84.62 \%$ & $77.78 \%$ & \\
\hline$\leq 23.8$ & $15.4 \%$ & $22.22 \%$ & NS \\
\hline \multicolumn{4}{|l|}{ MoCA } \\
\hline Adjusted scores & $22.77 \pm 4.45$ & $26.34 \pm 3.57$ & 0.0094 \\
\hline$E S=0(0 \rightarrow 17.362)$ & $17.31 \%$ & $0 \%$ & \\
\hline$E S=1-3(17.363 \rightarrow 23.361)$ & $46.15 \%$ & $15.38 \%$ & \\
\hline$E s=4(>23.361)$ & $36.54 \%$ & $84.62 \%$ & 0.0361 \\
\hline \multicolumn{4}{|l|}{ ROCF } \\
\hline Direct copy & $26.97 \pm 6.79$ & $28.56 \pm 10.58$ & NS \\
\hline$E S=0(\leq 28.87)$ & $52.9 \%$ & $25 \%$ & \\
\hline$E S=1-3(28.88 \rightarrow 32.40)$ & $17.7 \%$ & $25 \%$ & \\
\hline$E S=4(\geq 32.41)$ & $29.4 \%$ & $50 \%$ & $<0.001$ \\
\hline Delayed copy & $13.32 \pm 5.77$ & $12.75 \pm 7.0$ & NS \\
\hline$E S=0(\leq 9.46)$ & $21.4 \%$ & $33.3 \%$ & \\
\hline$E S=1-3(9.47 \rightarrow 14.73)$ & $42.9 \%$ & $33.3 \%$ & \\
\hline$E S=4(\geq 14.74)$ & $35.7 \%$ & $33.3 \%$ & $<0.001$ \\
\hline
\end{tabular}

Data are expressed either as mean \pm SD or percentage; Adjusted scores are classified into five equivalent scores (ES)

In agreement with literature data [35] different percentages of $\mathrm{MCl}$ prevalence in the COPD sample are reported depending on the type of instruments used. Using for all tests the ES classification the percentage of patients with preserved cognitive functions is higher in the GA carriers than in the GG (MoCA and ROCF)[36-37].

The QoL was evaluated with different instruments namely: SF-36, only at the baseline, ADL, IADL, SGQR, and MRF26 before and after PR [Table 3]. 
Table 3. Quality of life characteristics of the study population ( $N=70)$ stratified according to FKBP5 rs4713916 genotype (GG, GA), before and after Respiratory Rehabilitation.

\begin{tabular}{|c|c|c|c|c|c|c|}
\hline \multirow[t]{2}{*}{ Characteristics } & \multicolumn{3}{|c|}{ GG (N=57) } & \multicolumn{3}{|c|}{$\mathrm{GA}(\mathrm{N}=13)$} \\
\hline & Before PR & After PR & $\Delta$ & Before PR & After PR & $\Delta$ \\
\hline \multicolumn{7}{|l|}{ SF-36 } \\
\hline General Health & $73.21 \pm 12.49$ & & & $74.42 \pm 7.42$ & & \\
\hline Mental Health & $61.64 \pm 8.79$ & & & $67.67 \pm 9.26 *$ & & \\
\hline ADL & $5.15 \pm 1.72$ & $5.21 \pm 1.45$ & $0.06 \pm 2.0$ & $5.15 \pm 1.72$ & $5.61 \pm 0.96$ & $-0.46 \pm 0.88$ \\
\hline \multicolumn{7}{|l|}{ Degree of } \\
\hline \multicolumn{7}{|l|}{ Dependence** $^{* *}$} \\
\hline none & $65.95 \%$ & $75 \%$ & & $75 \%$ & $77.78 \%$ & \\
\hline 1 & $2.13 \%$ & 0 & & 0 & 0 & \\
\hline $2-3$ & $10.64 \%$ & $14.28 \%$ & & $8.33 \%$ & $22.22 \%$ & \\
\hline$>3$ & $21.28 \%$ & $10.72 \%$ & & $16.67 \%$ & 0 & \\
\hline IADL & $5.04 \pm 2.64$ & $5.97 \pm 2.54$ & $0.93 \pm 1.02$ & $5.82 \pm 1.47$ & $5.88 \pm 1.96$ & $0.06 \pm 0.18$ \\
\hline \multicolumn{7}{|l|}{ Degree of } \\
\hline \multicolumn{7}{|l|}{ Dependence *** } \\
\hline none & $36.17 \%$ & $57.14 \%$ & & $45.45 \%$ & $50 . \%$ & \\
\hline 1 & $17.02 \%$ & $17.87 \%$ & & $18.18 \%$ & $12.5 \%$ & \\
\hline $2-4$ & $29.79 \%$ & $10.71 \%$ & & $36.37 \%$ & $37.5 \%$ & \\
\hline$>4$ & $17.02 \%$ & $14.28 \%$ & & 0 & 0 & \\
\hline SGRQ & $51.55 \pm 15.36$ & $45.65 \pm 15.29$ & $-5.9 \pm 7.28$ & $40.25 \pm 16.62$ & $41.11 \pm 19.4$ & $0.86 \pm 5.43$ \\
\hline \multicolumn{7}{|l|}{ MRF-26 } \\
\hline Total score & $71.84 \pm 16.43$ & $52.23 \pm 18.94$ & $-19.60 \pm 22.32$ & $71.79 \pm 13.60$ & $45.73 \pm 18.68$ & $-26.07 \pm 13.01$ \\
\hline Daily Activities & $76.05 \pm 20.63$ & $56.33 \pm 20.68$ & $-19.73 \pm 25.72$ & $78.63 \pm 18.75$ & $46.15 \pm 19.23$ & $-32.48 \pm 14.28$ \\
\hline $\begin{array}{l}\text { Disability } \\
\text { Perceived }\end{array}$ & $67.87 \pm 15.78$ & $47.39 \pm 21.12$ & $-20.47 \pm 24.52$ & $64.96 \pm 16.95$ & $45.30 \pm 20.51$ & $-19.66 \pm 15.44$ \\
\hline General Health & $3.81 \pm 1.38$ & $2.90 \pm 1.74$ & $-0.90 \pm 1.45$ & $3.50 \pm 1.51$ & $2.38 \pm 1.60$ & $-1.12 \pm 1.25$ \\
\hline
\end{tabular}

Data are expressed as mean \pm SD or percentage $* p=0.0455 ;{ }^{* *} p<0.001$ Between before and after PR in GA patients; ${ }^{* * *} p=0.0025$ Between before and after PR in GG patients; $p=0.003$ at basal level between GG and GA patients; $p<0.001$ after rehabilitation between $G G$ and $G A$

The GA carriers show a basal SF-36 mental health score higher than GG carriers $(67.67 \pm 9.26$ vs61.64 $\pm 8.79 ; p<0.05)$. Patients carrying GA show a degree of independence in the daily activity (ADL) and in the use of instruments (IADL) higher than GG patients, independence that increases moderately after PR, i.e., $p<0.001$ and $p<0.0025$, respectively.

The psychological status of all patients is investigated with different instruments namely: BDI-II, CES-D, and SAS. CES-D is popular for estimating prevalence rates in relatively large samples, as potential 
indicators of depression [38-40]. To strengthen the evidence provided by the CES-D, two other scales such as the well-established BDI-II and the SAS were analyzed[38]. Table 4 shows all the results.

Table 4. Psychological status of the study population ( $N=70)$ stratified according to FKBP5 rs4713916 genotype $(G G, G A)$, at baseline. Data are expressed as mean \pm SD.

\begin{tabular}{|c|c|c|c|}
\hline Characteristics & GG (N=57) & GA ( $N=13)$ & $P^{*}$ \\
\hline BDI-II & $15.12 \pm 8.16$ & $5.80 \pm 2.17$ & 0.0054 \\
\hline CES-D & $12.50 \pm 10.07$ & $4.73 \pm 6.65$ & 0.0046 \\
\hline Depressive Affect & $3.10 \pm 4.62$ & $0.64 \pm 1.57$ & 0.0231 \\
\hline Well -Being & $4.21 \pm 2.77$ & $2.64 \pm 2.80$ & ns \\
\hline Somatic & $5.00 \pm 4.31$ & $1.45 \pm 2.77$ & 0.0043 \\
\hline Inter-Personal & $0.19 \pm 0.57$ & $0.0 \pm 0.0$ & ns \\
\hline SAS & $29.50 \pm 8.46$ & $22.55 \pm 2.25$ & 0.0017 \\
\hline $\begin{array}{l}\text { Affective } \\
\text { symptoms }\end{array}$ & $7.27 \pm 2.15$ & $5.67 \pm 1.12$ & 0.0104 \\
\hline Well-Being & $9.77 \pm 3.35$ & $7.00 \pm 1.94$ & 0.0111 \\
\hline $\begin{array}{c}\text { Somatic } \\
\text { symptoms }\end{array}$ & $22.50 \pm 6.84$ & $17.00 \pm 1.77$ & 0.0062 \\
\hline
\end{tabular}

The BDI-II, stating that a score of 13 or above is associated with presence of depressive symptoms, supports the observation that GG carriers show higher level of depressive symptoms in comparison with GA patients [15.12 \pm 8.16 versus $5.80 \pm 2.17, p=0.0054]$. At baseline, mean CES-D total score was higher in patients carrying GG than in GA patients $(12.65 \pm 10.26$ versus $4.73 \pm 6.65, p=0.0045)$ (Table 4). Specifically two domains such as depressive affect and somatic problem and retarded activity in GA carriers were not compromised.

SAS shows higher scores in GG carriers when compared to GA carriers[29.68 \pm 8.59 versus $22.55 \pm 2.25, p$ $=0.0017]$, specifically in the affective symptoms. Moreover both CES-D and SAS showed as GA carriers had 
a healthier perceived well-being than GG. In our sample $23.9 \%$ of GG carriers showed clinically significant symptoms of anxiety (score >36 SAS rating scale), with respect to none in GA carriers. Looking at each different symptomatic domain of SAS (Affective symptoms, Well-Being, Somatic symptoms) GA patients showed a significant high level of perceived healthiness.

Interestingly, looking at the medical history or respective families, $52.63 \%$ of GG carriers reported a history of psychiatric disorders in comparison with none among patients who are GA carriers $(p=0.0311)$.

The perceptions of illness and coping strategies are important determinants among factors influencing outcomes in COPD treatment [41-43]. Looking at the coping strategies, patient carriers GA in the FKBP5 gene show higher level of association with self-distraction and denial and moderate level with positive reframing and use of emotional support than GG carriers (Table 5).

Table 5. Associations between FKBP5 variant rs47139 and coping strategies in COPD patients ( $N=70)$. Patients are stratified according to FKBP5 rs4713916 genotype (GG, GA), at baseline. Data are expressed as mean \pm SD

\begin{tabular}{lccc}
\hline Characteristics & GG (N=57) & GA (N=13) & $\boldsymbol{p}$ \\
\hline Brief COPE $\dagger$ & & & $\mathrm{NS}$ \\
Acceptance & $5.205 \pm 1.773$ & $5.125 \pm 1.553$ & $\mathrm{NS}$ \\
Active coping & $6.455 \pm 1.731$ & $6.500 \pm 1.773$ & $\mathrm{NS}$ \\
Behavioral disengagement & $3.079^{* *}$ & $4.125 \pm 1.885$ & $0.018^{*}$ \\
Denial & $3.682 \pm 1.567$ & $4.877^{* *}$ & $\mathrm{NS}$ \\
Humor & $3.386^{* *}$ & $4.250 \pm 1.035$ & $\mathrm{NS}$ \\
Planning & $6.136 \pm 1.875$ & $6.875 \pm 1.458$ & $0.079^{*}$ \\
Positive Reframing & $4.659 \pm 1.916$ & $5.750 \pm 1.165$ & $\mathrm{NS}$ \\
Religion & $4.523 \pm 1.718$ & $5.250 \pm 2.053$ & $\mathrm{NS}$ \\
Self-blame & $4.591 \pm 1.730$ & $4.750 \pm 1.581$ & $0.007^{*}$ \\
Self-distraction & $4.886 \pm 1.660$ & $6.625 \pm 0.916$ & $\mathrm{NS}$ \\
Substance use & $2.201^{* *}$ & $2.250 \pm 0.707$ & $0.05^{*}$ \\
Use of emotional support & $4.273 \pm 1.453$ & $5.250 \pm 0.886$ & $\mathrm{NS}$ \\
Use of instrumental support & $4.432 \pm 1.531$ & $5.000 \pm 1.195$ & $\mathrm{NS}$ \\
Venting & $4.376^{*}$ & $5.125 \pm 1.246$ & \\
\hline
\end{tabular}

Data are expressed as mean \pm SD ; ${ }^{* * B a c k}$ transformed after logarithmic transformation; †Kruskal-Wallis test.

Moreover, only in the GA carriers self-distraction is positively correlated with positive reframing and acceptance as well as denial with venting and humor (data not shown). All significant data associations were confirmed using both the Kruskal-Wallis test and the Jonckheere-Terpstra trend test.

Among the drugs received by the patients, 32 (45.7\%) received drugs for neurological diseases (ATCC code N02-N07). Figure 1 and Table 6 show that the percentage of GG carriers receiving these drugs is 
higher $(27.15 \%)$ than that of GA carriers $(5.7 \%)(p<0.001)$. Specifically GG carriers received more antianxiety, antidepressant, anti-psychotic, hypnotic-sedative drugs than GA.

Figure 1. Patients receiving Drugs for Neurological disease.

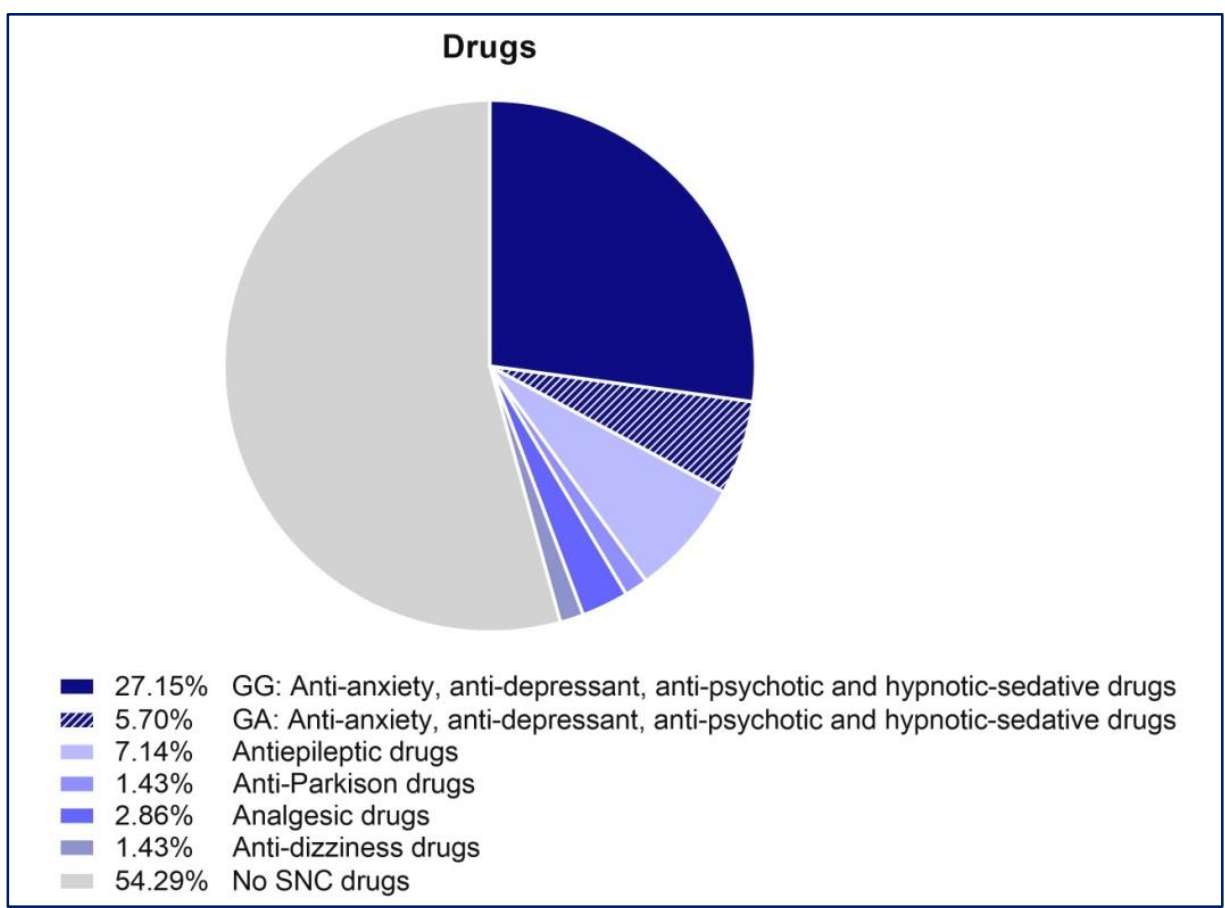

Table 6.Percentage of patients receiving Drugs for Neurological disease. Patients are stratified according to FKBP5 rs4713916 genotype (GG, GA).

\begin{tabular}{lccc}
\hline DRUGS & Patients \% & Genotype GG \% & Genotype GA \% \\
\hline $\begin{array}{l}\text { Anti-Anxiety,Antidepressant,Antipsychotic, } \\
\text { Hypnotic-Sedative }\end{array}$ & 32.86 & 27.14 & 5.7 \\
Antiepileptic & 7.14 & 5.71 & 1.43 \\
Anti-Parkinson & 1.43 & 1.43 & 0 \\
Analgesic & 2.86 & 2.86 & 0 \\
Anti- Dizziness & 1.43 & 1.43 & 0 \\
\hline
\end{tabular}

No association with personal smoking/alcohol drinking habits and medical family disease history, including respiratory illness, has been observed.

\section{Discussion}


FKBP5 rs4713916 is associated not only with a better response to rehabilitation in terms of pulmonary functions (6MWD and FEV1) [23] but also influences positively cognitive performance, QoL, anxiousdepression symptoms and stress coping behavior. Specifically the GA carriers when compared to GG carriers show 1) Better cognitive performances ,2) Higher degree of independence both in the daily activity and in the use of instruments, 3) Better QoL before and after rehabilitation, 4) No presence of depressive mood and anxiety symptoms, 5) No family history of psychiatric disorder, 6) More ability to cope with stressors by avoiding emotions in active and direct way but at the same time demanding emotional support, and 7) Lesser use of anti-anxiety, anti-depressant anti-psychotic, hypnotic-sedative drugs. Of note both GA and GG carriers show the same number of comorbidities of the same diseases (see Table 1).

This is the first study showing that FKBP5 rs4713916 is related to cognitive performance. In a previous work it has been reported that FKBP5 rs1360780 (C:T) is associated with cognitive function in a non-clinical population aged more than 50 years. Specifically, individuals carrying the $T$ allele showed poorer attention/concentration (working memory) compared with individuals carrying the $G$ allele [44]. In our study patients carrying rs4713916A allele showed better performance in the cognitive tests (MoCA and ROCF).

The MMSE for the score range $23.9-30$ shows a little better performance for GG (84.62\% versus $77.78 \%)$, although this test is not the most appropriate instrument to evaluate $\mathrm{MCI}$ [45-47], and therefore we used in our group of COPD patients also the MoCA that includes executive tests, and allows to identify nonamnestic $\mathrm{MCl}[48,36],[49-52]$. It has been reported that rs30800373 and rs4713916 are in linkage disequilibrium with rs1360780 thus their effects are supposed to be related to the same mechanism [53].

These results are supported by the observation that patients carrying the A allele show a degree of independence in the ADL and specifically in the IADL higher than GG patients, independence that increases significantly after PR. Thus, it has been reported by an Italian longitudinal study on aging that the inclusion of IADL in the $\mathrm{MCl}$ construct significantly improves the prediction of dementia [54]. Finally GA patients show a tendency to have a basal SF-36 mental health score higher than GG carriers. 
Despite our sample consisted of patients suffering from COPD, subjects carrying FKBP5 rs4713916 GA show absence of anxious-depression symptoms. A number of previous studies investigated the possible mechanism linking systemic inflammation(COPD is considered an inflammatory disease) and depression [55-56]. Although poorly understood, mechanisms underlying depression in COPD are likely multifactorial and may include biological factors (i.e. oxidative damage) [24], disease-related features (i.e. dyspnea, breathless, cough, difficult to walk, multi-morbidity) and psychological and social correlates including social isolation and experiencing traumatic life events as bereavement. Other studies point out to different types of inflammatory marker (cytokines) such as interleukins (IL-1 $\beta$, IL-6, interferon- $-[$ IFN- -$]$ ) and tumor necrosis factor (TNF) and pathogenesis of major depressive disorder (MDD) [57-60]. Specifically high level of IL-6 are related to MDD, thusIL-6 concentrations are significantly positively associated with Hamilton Depression Scale-17 scores in depressive patients [60]. In a previous study [24] we evaluated the serum level of IL-6 in the same patients analyzed also in this study. When the data of serum level of IL-6 is stratified for FKBP5 rs4713916it is found that the level are lower in GA carriers than in GG $(50.96 \pm 43.78$ versus 220.7 $\pm 202.6 \mathrm{pg} / \mathrm{ml} ; \mathrm{p}=0.0022$ according to Mann-Whitney test). It has been reported that COPD, depression, and COPD with comorbid depression are associated with increased IL-6 levels when compared with healthy controls [61-62].

FKBP5 is considered as a candidate gene for investigating how negative life events may interact with genetic susceptibility to stress-related psychiatric symptoms. This evidence is supported also by a metaanalysis involving 12,491 patients and 14,091 healthy controls which showed as rs4713916 is associated with major depressive disorder susceptibility [63], and thus the major allele (G) is more common among patients than controls. The association was stronger in females than in the whole population. The homozygote carriers of the major allele $(\mathrm{GG})$, which is associated with the clinical diagnosis, showed less reduction of cortisol secretion in the Dexamethasone/Corticotropin-Releasing Hormone test after 4 weeks of standardized depression treatment with citalopram, a selective serotonin reuptake inhibitor, compared to carriers of the minor allele (A) [64]. Moreover, there is an association between rs4713916 and remission with citalopram treatment in the Caucasian population [65]. 
It has been reported that: (i) FKBP5 is responsive to stress exposure and elevated glucocorticoid levels, which affects subsequent transcription of FKBP5 [66]. (ii) When FKBP5 binds to the GR complex, the affinity for cortisol decreases, resulting in GR resistance and affecting cortisol output [66], thus FKBP5 acts as an inhibitor of the GR-mediated glucocorticoid action. (iii) GCSs induce FKBP5 expression as part of an intracellular "ultrashort" negative feedback loop for GR activity [67]. (iv) In the absence of GCSs, FKBP5 can decrease the affinity of GR to corticosteroids by a complex interaction with the mature GR, thus leading to weakened GR signaling[68]. (v) Three variants in the FKBP5 gene namely rs4713916, rs1360780, rs3800373, that are in LD [53] are associated with an incomplete normalization of stress-elicited cortisol secretion in healthy subjects after psychosocial stress. The strongest association was revealed for rs3800373 and rs4713916 [69]. (vi) In non-exposed individuals carrying the A allele rs4713916 protects against the development of depression [68]. Hence, in the context of GCSs therapy in COPD patients, an inherited capacity to normalize the GCSs response may have a pleiotropic effect. By one side, this hypothesized capacity might decrease the earlier drug responsiveness (as shown in Chron's disease) [70] but, on the other side, it might prevent undesired effects associated with long term GCSs therapy, thus contributing to ameliorate the response to PR [23].

All of these observations suggest a genotype-dependent risk of chronically elevated plasma cortisol levels in the context of chronic or recurrent stress, which also may increase the risk of stress related disorders, such as depression [71].

Several studies have shown that psychological distress influences QoL and predicts exercise capacity better than pulmonary functioning [69]. Psychological distress increases a physical and social malfunctioning, inadequate adherence to therapy, more medical visits and hospital re-admissions, and mortality risk [71]. Moreover, many studies suggest that there is a high prevalence of anxiety and depression disorders in COPD patients and often they appear together [72]. These symptoms reduce the health outcomes in terms of exercise tolerance, QoL and exacerbations. It has been suggested that coping strategies may play an important role in mediating the relationship between personal resources such as knowledge of the disease, self-efficacy and social support and psychological responses such as depression 
and anxiety in COPD patients [73]. We reported, recently, that the change in distance ( $\Delta 6 \mathrm{MWD})$ between final and baseline value in meters is positively associated with Self-distraction, Active Coping, and Planning strategies [22].

We can speculate that GA carriers have more cognitive and psychological resources to better adapt and manage their chronic health conditions (i.e. COPD and multi-morbidity). Figure 2 summarizes the phenotype of subjects carrying rs4713916 evaluated in our study.

Figure 2. Schematic representation of the influence of the GA genotype on clinical, cognitive, and psychological features of COPD patients undergoing pulmonary rehabilitation

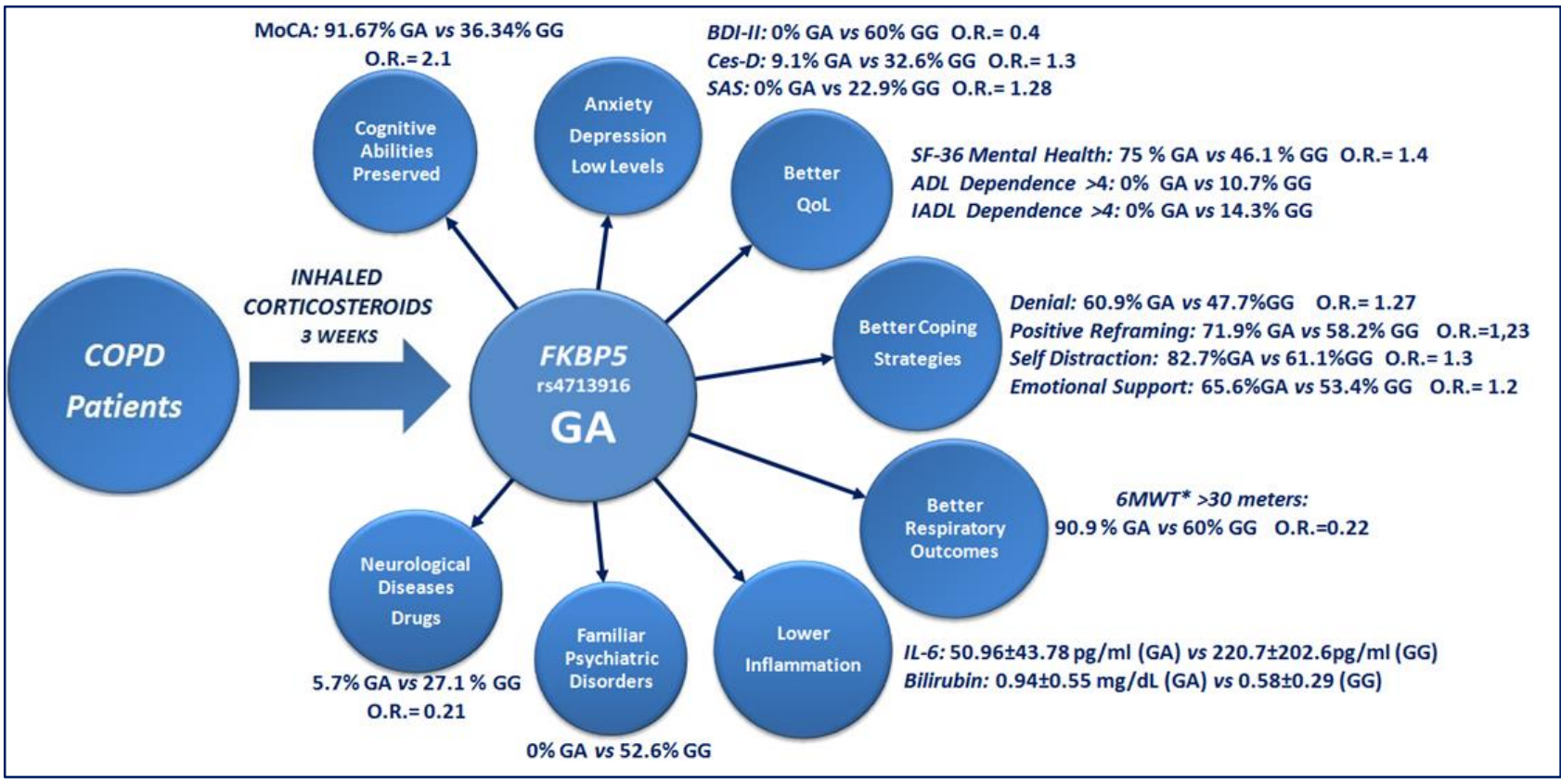

COPD is characterized not only by dyspnea, chronic cough, and sputum production but also by multimorbidity including CVD, sarcopenia, osteoporosis, diabetes and extrapulmonary brain-related disorders such as depression, anxiety and cognitive problems [1-4]. The brain-related comorbidities in COPD patients are related to worsening of symptoms and increased mortality that may be related to 1) compliance reduction, 2) worsened perception of dyspnea possibly leading to increased hospital admissions and 3) the worsened ability of depressed and/or anxious patients to cope with a chronic disease. Moreover, impaired cognitive function may be related to poor health status, increased rate and longer hospitalization, exclusion from or not completing pulmonary rehabilitation programs, lower therapy adherence and selfmanagement. 
Undoubtedly different underlying biological processes such as systemic inflammation, hypoxia, oxidative stress, smoking, corticosteroid usage and the gut microbiome are involved. Each mechanism may show overlapping link(s) with another, building a complex interaction network between all mechanisms and the onset of depression, anxiety, cognitive impairment and COPD symptoms.

Recently, a new study describes the presence of a specific "Psychologic" comorbidity cluster related to COPD not present in matching aging control population [74]. This cluster in respect to the clinical characterization, is distinguished by the worst QoL. The smaller occurrence of mood disorders in the matching aging control population may be the cause of the absence of a "Psychologic" cluster in this population. Remarkably, the frequency of exacerbation, the severity of the dyspnea, and the functional exercise performance were similar amongst all COPD comorbidity clusters. These observations highlight over the need of a detailed phenotyping beyond the above-mentioned clinical outcomes.

Most likely, patients carrying FKBP5 rs4713916 GA do not fall into the "Psychologic" comorbidity cluster. On the other hands COPD patients carrying FKBP5 rs4713916 GG may fall in the "Psychologic" comorbidity cluster with psychological conditions representing an important subgroup for targeted mechanistic and intervention studies. Thus it is possible that GA carriers benefit more of the PR than GG carriers.

\section{Strengths and Limitations}

Our study has several strengths. First, this is a real-life study. The number of real-life studies on COPD is increasing [75], but the amount of available data other than remission and/or exacerbations is limited. This study provides a multiperspective evaluation of COPD patients starting from a genetic make-up characterization, and provides a molecular basis in support of the theory by Triest et al. [74], concerning the presence of a "Psychologic" comorbidity cluster, specific only for COPD patients. Moreover, the assessment of the QoL in a real-life setting is critical to estimate the adherence and the compliance to treatment. The study shows that chronic patients - not recruited for a RCT study - may accept to participate to a study that includes requests normally not required to their treatment. This observation suggests that in real-life the most important factor determining the acceptance of a new protocol is the attitude of a person toward their health as a result of four major groups of determinants: the perceived severity of a condition, 
the perceived susceptibility to that condition, the benefits of taking a preventive action, and the barriers to taking that action.

The major limitation of the study is the small sample size that did not allow for the definitive identification of a genetic cluster. However, the number of patients analyzed in this study is absolutely consistent with its nature of pilot study, as confirmed by the algorithm proposed by Viechtbauer et al [76] for pilot studies.

\section{Methods}

\subsection{Subjects}

The study was approved by the IRCCS San Raffaele Pisana Ethical Committee (Prot 15/2013) and all participants gave separate consent to participate to clinical and genetic studies. The study has a interventional non pharmacological design, and enrolled in70 consecutive patients, aged 70 years or older, suffering from GOLD 3-4 COPD [1], and admitted to the San Raffaele Pisana Pulmonary Rehabilitation Unit (PRU) between January 2013 and December 2015 for a comprehensive 3 weeks PR program. All patients were part of a larger study on the application of Systems Medicine approaches in real life evaluated with a multidisciplinary and multidimensional assessment [77] .

The following patient characteristics weremeasured:1)Demographics (age, gender, marital status, employment status, educational); 2) Medical history and life-style [i.e. tobacco smoking status; alcoholdrinking, familiarity for COPD or additional diseases, comorbidities]; 3) Body Mass Index (BMI); 4) Cognitive and psychological clinical alterations/disorders; 5) QoL and Health-related QoL; 6) Coping strategies; 7) Pharmacologic therapy.

\section{2 rs4713916 analysis}

Detailed methods for the genotyping of rs4713916 are described in a previous publication [23.].

In summary, rs4713916 was genotyped MBK_FKBP5 90 kits from Diatheva SrL (Italy) according to company instructions. A is the minor allele of the SNP, the homozygous AA samples were not present in our sample. The homozygous GG samples are present at $80.3 \%$ and the GA 13 at $18.3 \%$ in our sample. 


\subsection{Instruments}

The Mini-Mental State Examination (MMSE) is a brief 30-point questionnaire to evaluate cognitive performance. Scores are adjusted for age and education according to the Magni et al. distribution [78]. Therefore, in this study we defined $\mathrm{MCl}$, as proposed by Pierobon et al. [50] as present when MMSE score is 18.3-23.8 and not present when MMSE scores are>23.8 [50].

The Montreal Cognitive Assessment (MoCA) is a cognitive screening instrument developed to detect $\mathrm{MCl}$. The MoCA assesses multiple cognitive domains, including, memory, language, executive functions, visuospatial skills, calculation, abstraction, attention, concentration, and orientation[48]. Raw scores are adjusted for age, education and gender. Adjusted scores are obtained by adding or subtracting the contribution of concomitant variables from the original scores [36]. The adjusted scores are classified into five equivalent scores $(\mathrm{ES})$. In this study we defined $\mathrm{MCl}$ as present for $\mathrm{ES}=0 \pm 1$ and not present for $\mathrm{ES}=$ $2 \pm 4$, accordingly to Pierobon et al. [50].

The Rey-Osterrieth complex figure test (ROCF) is a widely used neuropsychological test for the evaluation of visuospatial constructional ability and visual memory. ROCF includes 18 units and the maximum score for each of the two tasks (direct and delayed copying) is 36 . The adjusted cut-off is: direct copy 28, delayed copy 6.2. The scores are normalized to five ES according to Caffarra et al.[36].

The Beck Depression Inventory (BDI-II) is a self-rating scale of 21 items to explore the severity of depression according to diagnostic criteria of depressive disorders listed in the Diagnostic and Statistical Manual of Mental Disorder, Fourth Edition (DSM-IV) [79, 80.] that covers the classification of major depressive disorder as defined in the fifth edition of the DSM-5 [40]. The range is from 0 to 63 , a score of $13 / 14$ or above is indicative of depressive symptoms) [79].

The Center for Epidemiologic Studies Depression Scale (CES-D, range from 0 to 60) [81] is a brief selfreport scale designed to measure self-reported symptoms associated with depression experienced in the past week [82]. The CES-D contains 20 items measuring depressive signs experienced during the previous seven days on a four-point Likert scale (from 0 , never or rarely to 3 , most days or every day). The maximum total score is 60 . A score $\geq 16$ suggests the presence of clinical depression. In the current study 
the internal consistency was expressed by a Cronbach's alpha of 0.83 [83]. The Item Factor Analyses was conducted according to Hertzog et al [84]. Four separated factors were identified as: depressive affect; well-being, somatic problem and retarded activity and inter-personal difficulties.

The Zung Self-Rating Anxiety Scale (SAS)focuses on the most common general anxiety disorders. It is a likert scale, with raw scores that range from 20 to 80 . A raw score $>36$ is considered clinically relevant [85].

The 36-Item Short Form Health Survey (SF-36,scores range from 0 to 100)provides a direct quantitative indication of an individual's health status and, as it is easy to administer, it has become the most widelyused QOL evaluation tool in the world [86].

The Activities of Daily Living (ADL)refers to people's daily self care activities with questions aiming to evaluate the functional independence/dependence of subjects in bathing, dressing, going to toilet, transferring, continence, and feeding[87]. The degree of dependence is categorized as none, or dependence in one, 2-3 or $>4$ [54].

The Instrumental Activities of Daily Living (IADL) refers to more sophisticated tasks of everyday life, more demanding in terms of cognitive function such as using the telephone, managing money[88].The score range for ADL is from 0 to 6 [0 total dependence- 6 none], for IADL from 0 to 8 for woman and from Oto 5 for man [0 total dependence, 5/8 none].The degree of dependence is categorized as none, or dependence in 1, 2-4 or $>4$ [54].

The St. George's Respiratory Questionnaire (SGRQ, scores range from 0 to 100) is a questionnaire based on empirical data and interviews with patients for measuring impaired health and perceived well-being in airways disease. A mean change score of 4 units is associated with slightly efficacious treatment, 8 units for moderately efficacious change and 12 units for very efficacious treatment [87].

The Maugeri Foundation Respiratory Failure Questionnaire (MRF 26, scores range from 0 to 5)has two domain scores - activity, perceived impairment - and a total score. It has been demonstrated to be a good instrument to measure QoL impairment in the chronic respiratory failure (CRF) setting irrespective of the underlying disease [90]. 
The Cumulative Illness Rating Scale (CIRS), is one of the existing tools to measure multimorbidity. This index measures the chronic medical illness burden while taking into consideration the severity of chronic diseases. Initially developed by Linn et al. [89], the CIRS was later revised by Miller et al. [92] to reflect common problems of the elderly. We used the 14-system version of Miller et al. [92] to measure the chronic medical illness burden in a family practice clientele. The final score of the CIRS is the sum of each of the 14 individual system scores. The scoring may theoretically vary from 0 to 56 although a very high score is impossible because it would represent several system failures not compatible with life.

The Brief COPE is a self-report questionnaire developed to assess a broad range of coping responses. Currently, it is one of the best validated and most frequently used measures of coping strategies. The Brief COPE is an abbreviated version of the COPE inventory (coping orientation to problems experienced) [93]. The Brief COPE measures 14 theoretically identified coping responses: Self-distraction, Active coping, Denial, Substance use, Use of emotional support, Use of instrumental support, Behavioral disengagement, Venting, Positive reframing, Planning, Humor, Acceptance, Religion, and Self-blame. It represents a way to rapidly assess coping responses because it is a short 28-item self-report questionnaire with two items for each of the measured coping strategies. The range is from 2 to 8 with higher scores indicating increased use of that specific coping strategy.

\subsection{Drug Therapy}

All patients received daily ICS [beclomethasone dipropionate: $\left.\mathrm{C}_{28} \mathrm{H}_{37} \mathrm{ClO}_{7}\right] 0.4 \mathrm{mg} / \mathrm{ml}$ in combination with two bronchodilators such as one SABA [i.e. salbutamol: $\mathrm{C}_{13} \mathrm{H}_{21} \mathrm{NO}_{3}$ ] and one 120 SAMA [anti subtype M3, i.e. ipratropium bromide: $\mathrm{C}_{20} \mathrm{H}_{30} \mathrm{BrNO}_{3}$ ] for 3 weeks. Exacerbations were treated with oral $\mathrm{CSs}$ prednisone $\left[\mathrm{C}_{21} \mathrm{H}_{26} \mathrm{O}_{5}\right]$ at 5 or $25 \mathrm{mg}$, or betamethasone $\left[\mathrm{C}_{22} \mathrm{H}_{29} \mathrm{FO}_{5}\right]$ at $1.5 \mathrm{mg}$ or with injectable methylprednisolone $\left[\mathrm{C}_{22} \mathrm{H}_{30} \mathrm{O}_{5}\right]$ at $20 \mathrm{mg}$. 


\subsection{Statistical Analysis}

Data were managed and analyzed using STATA12, and GraphPad Prism 8.1 (GraphPad Software Inc., La Jolla, CA, USA). Continuous variables were logarithmically transformed to normalize the distribution. Difference in the distribution of studied endpoints according to genotype were tested using test or $\mathrm{Chi}^{2}$; when the assumption of normality could not be verified the Kruskal-Wallis test; Jonckheere-Terpstra trend test. Spearman correlation was used to compare Brief COPE between different genotypes.

Continuous data were described as mean \pm SD (Standard deviation). A p-value $\leq 0$ of 0.05 was considered as statistically significant.

\section{Conclusions}

Our study shows that rs4713916 is positively associated with better outcome for COPD. These results offer valuable insights into the role of FKBP5 in the complex network of mechanisms associated to clinical and behavioral features of COPD patients. Our data may be used as initial benchmark for future clinical studies. 


\section{Abbreviations}

6MWD- six minutes walking distance

6MWT - six minutes walking test

$A D L$ - activities of daily living

BDI-II - Beck depression inventory

BMI - body mass index

CES-D - center for epidemiologic studies depression scale

CIRS- cumulative illness rating scale

COPD - chronic obstructive pulmonary disease

CVDs - cardiovascular diseases

FEV1 - forced expiratory volume in $1 \mathrm{~s}$

GCSs - glucocorticosteroids

GR - glucocorticoids receptor

GREs - glucocorticoid responsive elements

IADL - instrumental activities of daily living

ICS - inhaled corticosteroids

IL - interleuchin

LABA - long-acting $\beta$-agonists

LAMA - long-acting muscarinic antagonists

LD - linkage disequilibrium

LTOT - long term oxygen therapy

$\mathrm{MCl}$ - mild cognitive impairment

MDD - major depressive disorder

MMSE - mini-mental state examination

MoCA - Montreal cognitive assessment

MRF26 - Maugeri foundation respiratory failure questionnaire

NCD - non communicable disease

NICE - national institute for health and care excellence

PR - pulmonary rehabilitation

PRU - pulmonary rehabilitation unit

QoL - quality of life

ROCF - Rey-Osterrieth complex figure test

SAS - Zung self-rating anxiety scale

SD - standard deviation

SF-36 - 36-item short form health survey general

SGRQ - Saint George's respiratory questionnaire

SNPs- single-nucleotide polymorphisms

TNF - tumor necrosis factor

Funding: Part of this study was supported with the contribution of the Italian Ministry of Health

Acknowledgements: This study was supported by San Raffaele Pisana institutional grant. We are extremely grateful to the staff of San Raffaele Pisana and specifically to Astrid van Rijn for supporting in this study.

Conflict of interest: No potential conflicts of interest were disclosed. 


\section{References}

1. GOLD 2019, global strategy for the diagnosis, management, and prevention of chronic obstructive pulmonary disease 2019. Report and strategies. Available online: https://goldcopd.org/wp-content/uploads/2018/11/GOLD-2019-v1.7FINAL-14Nov2018-WMS.pdf (accessed on April 2019).

2. Vanfleteren, L.E.G.W.; Spruit, M.A.; Wouters, E.F.M.; Franssen, F.M.E. Management of chronic obstructive pulmonary disease beyond the lungs. Lancet Respir Med. 2016, 4(11), 911-924.

3. Franssen, F.M.; Rochester, C.L. Comorbidities in patients with COPD and pulmonary rehabilitation: do they matter? Eur Respir Rev. 2014, 23(131), 131-41.

4. European Lung Foundation. Lung diseases COPD. Lung disease \& information. 2012. Available online: http://www.europeanlung.org/en/lung-disease-and-information/lung-diseases/copd (accessed on April 2019).

5. Quaderi, S.A.; Hurst, J.R. The unmet global burden of COPD. Glob. Health Epidemiol. Genom. 2018, 3, e4.

6. Gayle, A.V.; Axson, E.L.; Bloom, C.I.; Navaratnam, V.; Quint, J.K. Changing causes of death for patients with chronic respiratory disease in England, 2005-2015. Thorax. 2019, 74(5), 483-491.

7. Miller, J.; Edwards, L.D.; Agusti, A. et al. Comorbidity, systemic inflammation and outcomes in the ECLIPSE cohort. Respir Med. 2013, 107(9), 1376-84.

8. Rabe, K.F.; Watz, H. Chronic obstructive pulmonary disease. Lancet. 2017,389(10082), 1931-1940.

9. Spruit, M.A.; Wouters, E.F.M. Organizational aspects of pulmonary rehabilitation in chronic respiratory diseases. Respirology. 2019 [Epub ahead of print]

10. Pollok, J.; van Agteren, J.E.; Esterman, A.J.; Carson-Chahhoud, K.V. Psychological therapies for the treatment of depression in chronic obstructive pulmonary disease. Cochrane Database Syst Rev. 2019, 3, CD012347. [Epub ahead of print].

11. Pooler, A.; Beech, R. Examining the relationship between anxiety and depression and exacerbations of COPD which result in hospital admission: a systematic review. Int J Chron Obstruct Pulmon Dis. 2014, 9, 315-30.

12. Brenes, G.A. Anxiety and chronic obstructive pulmonary disease: prevalence, impact, and treatment. Sychosom Med. 2003, 65, 963-970

13. Panagioti, M.; Scott, C.; Blakemore, A.; Coventry, P.A. Overview of the prevalence, impact, and management of depression and anxiety in chronic obstructive pulmonary disease. Int J Chron Obstruct Pulmon Dis. 2014, 9, 1289-306.

14. Pelgrim, C.E.; Peterson, J.D.; Gosker, H.R.; Schols, A.M.W.J.; van Helvoort, A.; Garssen, J.; Folkerts, G.; Kraneveld, A.D. Psychological co-morbidities in COPD: Targeting systemic inflammation, a benefit for both? Eur J Pharmacol. 2019, 842, 99-110.

15. Vanfleteren, L.; Spruit, M.; Franssen, F.M. Clusters of comorbidities based on validated objective measurements and systemic inflammation in patients with chronic obstructive pulmonary disease. Am. J. Respir. Crit. Care Med.2013, 187(7), 728-35.

16. National Institute for Health and Care Excellence. Multimorbidity: Clinical Assessment and Management. Available online: www.nice.org.uk/guidance/indevelopment/gid-cgwave0704/documents (accessed on April 2019).

17. Kernick, D.; Chew-Graham, C.A.;O'Flynn, N. Clinical assessment and management of multimorbidity: NICE guideline. Br. J. Gen. Pract. 2017, 67(658), 235-236.

18. Augustin, I.M.; Wouters, E.F.M. Process of pulmonary rehabilitation and program organization. J. Card. Pulm. Rehabil. 2017, 1, 109.

19. NIH Medical Rehabilitation Coordinating Committee. National Institutes of Health research plan on rehabilitation. Assist. Technol. 2017. 
20. Wagner, A.K. TBI Rehabilomics Research: an Exemplar of a Biomarker-Based Approach to Precision Care for Populations with Disability. Curr. Neurol. Neurosci. Rep. 2017,17,84, 1-8.

21. Russo, P.; Prinzi, G.; Lamonaca, P.; Cardaci, V.; Fini, M. Flavonoids and Reduction of Cardiovascular Disease (CVD) in Chronic Obstructive Pulmonary Disease (COPD). Curr. Med. Chem. 2018.

22. Russo, P.; Prinzi, G.; Kisialiou, A.; Cardaci, V.; Stirpe, E.; Conti, V.; Fini, M.; Bonassi, S. Action plans and coping strategies in elderly COPD patients influence the result of pulmonary rehabilitation: an observational study. Eur. J. Phys. Rehabil. Med.2017

23. Russo, P.; Tomino, C.; Santoro, A.; Prinzi, G.; Proietti, S.; Kisialiou, A.; Cardaci, V.; Fini, M.; Magnani, M.;Collacchi, F.; et al.FKBP5 rs4713916: A Potential Genetic Predictor of 2 Interindividual Different Response to Inhaled 3 Corticosteroids in Patients with Chronic Obstructive 4 Pulmonary Disease in real life setting. Int. J. of Mol. Sci.2019, 20(8).

24. Russo, P.; Lamonaca, P.; Milic, M.; Rojas, E.; Prinzi, G.; Cardaci, V.; Vitiello, L.; Proietti, S.; Santoro A.; et al. Biomarkers of DNA damage in COPD patients undergoing pulmonary rehabilitation: Integrating clinical parameters with genomic profiling. Mut. Res. - Gen. Tox. and Env. Mut. 2019.

25. Collins, F.S.; Varmus, H. A new initiative on precision medicine. N. Engl. J. Med. Overseas Ed. 2015, 372(9), $793-795$.

26. Hobbs, B.D.; de Jong, K.; Lamontagne, M.; Bossé, Y.; Shrine, N.; Artigas, M.S.; Wain, L.V.; Hall, I.P.; Jackson, V.E.; Wyss, A.B.; et al. Genetic loci associated with chronic obstructive pulmonary disease overlap with loci for lung function and pulmonary fibrosis. Nat. Genet. 2017, 49, 426-432.

27. Li, Y.; Cho, M.H.; Zhou, X. What do polymorphisms tell us about the mechanisms of COPD? Clin. Sci. 2017, 131, 2847-2863

28. Wain, L.V.; Shrine, N.; Artigas, M.S.; Erzurumluoglu, A.M.; Noyvert, B.; Bossini-Castillo, L.; Obeidat, M.; Henry, A.P.; Portelli, M.A.; Hall, R.J.; et al. Genome-wide association analyses for lung function and chronic obstructive pulmonary disease identify new loci and potential druggable targets. Nat. Genet. 2017, 49, 416-425.

29. Russo, P.; Lococo, F.; Kisialiou, A.; Prinzi, G.; Lamonaca, P.; Cardaci, V.; Fini, M. Pharmacological Management of Chronic Obstructive Lung Disease (COPD). Focus on Mutations. Curr. Med. Chem. 2018 [Epub ahead of print].

30. Matosin, N.; Halldorsdottir, T.; Binder, E.B. Understanding the Molecular Mechanisms Underpinning Gene by Environment Interactions in Psychiatric Disorders: The FKBP5 Model. Biol. Psychiatry. 2018 , 83(10),821-830.

31. Pelleymounter, L.L.; Moon, I.; Johnson, J.A.; Laederach, A.; Halvorsen, M.; Eckloff, B.; Abo, R.; Rossetti, S.A novel application of pattern recognition for accurate SNP and indel discovery from high-throughput data: Targeted resequencing of the glucocorticoid receptor co-chaperone FKBP5 in a Caucasian population. Mol. Genet. Metab. 2011,104, 457-46

32. Hubler, T.R.; Scammell, J.G. Intronic hormone response elements mediate regulation of FKBP5 by progestins and glucocorticoids. Cell. Stress Chap. 2004,9, 243-252.

33. Fries, G.R.; Gassen, N.C.; Rein, T. The FKBP51 Glucocorticoid Receptor Co-Chaperone: Regulation, Function, and Implications in Health and Disease. Int J. Mol. Sci. 2017, 5;18(12).

34. WHO. Obesity and overweight. Available online: http://www.who.int/mediacentre/factsheets/fs311/en/ (accessed on May 2019).

35. Dodd, J.W.; Getov, S.V.; Jones, P,W. Cognitive function in COPD. Eur. Respir J.2010, 35, 913-22.

36. Conti, S.; Bonazzi, S.; Laiacona, M.; Masina, M.; Coralli, M.V. Montreal Cognitive Assessment (MoCA)-Italian version: regression based norms and equivalent scores. Neurol. Sci. 2015, 36(2),209-14.

37. Caffarra, P.; Vezzadini, G.; Dieci, F.; Zonato, F.; Venneri, A. Rey-Osterrieth complex figure: normative values in an Italian population sample. Neurol Sci.2002, 22(6), 443-7.

38. Shafer, A.B. Meta-analysis of the factor structures of four depression questionnaires: Beck, CES-D, Hamilton, and Zung. J.Clin. Psychol. 2006, 62, 123-146. 
39. Diagnostic and Statistical Manual of Mental Disorders, Fifth Edition Edited by American Psychiatric Association. Available online: http://dsm.psychiatryonline.org/doi/book/10.1176/appi.books.9780890425596 (accessed on May 2019).

40. Uher, R.; Payne, J.L.; Pavlova, B.; Perlis, R.H. Major depressive disorder in DSM-5: implications for clinical practice and research of changes from DSM-IV. Depression and Anxiety. 2014.

41. Vaske, I.; Kenn, K.; Keil, D.C.; Rief, W.; Stenzel, N.M. Illness perceptions and coping with disease in chronic obstructive pulmonary disease: effects on health-related quality of life. J. Health Psychol. 2017, 22, 1570-1581

42. Stoilkova-Hartmann, A.; Janssen, D.J.; Franssen, F.M.; Wouters, E.F. Differences in change in coping styles between good responders, moderate responders and non-responders to pulmonary rehabilitation. Respir. Med. 2015,109, 1540-1545

43. Lee, H.; Yoon, J.Y.; Kim, I.; Jeong, Y.H. The effects of personal resources and coping strategies on depression and anxiety in patients with chronic obstructive pulmonary disease. Heart Lung. 2013, 42, 473-479.

44. Fujii, T.; Ota, M.; Hori, H.; Hattori, K.; Teraishi, T.; Matsuo, J.; Kinoshita, Y.; Ishida, I.; Nagashima, A.; Kunugi, H. The common functional FKBP5 variant rs1360780 is associated with altered cognitive function in aged individuals. Sci. Rep. $2014,4,6696$.

45. Cameron, J.; Worrall-Carter, L.; Page, K.; Stewart, S.; Ski, C.F. Screening for mild cognitive impairment in patients with heart failure: Montreal cognitive assessment versus mini mental state exam. Eur. J. Cardiovasc. Nurs. 2013, 12(3), 252-60.

46. Fu, C.; Jin, X.; Chen, B.; Xue, F.; Niu, H.; Guo, R.; Chen, Z.; Zheng, H.; Wang, L.; Zhang, Y. Comparison of the MiniMental State Examination and Montreal Cognitive Assessment executive subtests in detecting post-stroke cognitive impairment. Geriatr. Gerontol. Int. 2017,17(12),2329-2335.

47. Lam, B.; Middleton, L.E.; Masellis, M.; Stuss, D.T.; Harry, R.D.; Kiss, A.; Black, S.E. Criterion and convergent validity of the Montreal cognitive assessment with screening and standardized neuropsychological testing. J. Am. Geriatr Soc. 2013,61(12),2181-5.

48. Nasreddine, Z.S.; Phillips, N.A.; Bédirian, V.; Charbonneau, S.; Whitehead, V.; Collin, I.; Cummings, J.L.; Chertkow, H. The Montreal Cognitive Assessment, MoCA: a brief screening tool for mild cognitive impairment. J Am Geriatr Soc. 2005,53(4),695-9.

49. Bajaj, M.K.; Burrage, D.R.; Tappouni, A.; Dodd, J.W.; Jones, P.W.; Baker, E.H. COPD patients hospitalized with exacerbations have greater cognitive impairment than patients hospitalized with decompensated heart failure. ClinInterv Aging. 2018, 14, 1-8.

50. Pierobon, A.; Ranzini, L.; Torlaschi, V.; Sini-Bottelli, E.; Giardini, A.; Bruschi, C.; Maestri, R.; Callegari, S.; Raccanelli, R.; Sommaruga, M. Screening for neuropsychological impairment in COPD patients undergoing rehabilitation. PLoS One.2018, 13(8), e0199736

51. Villeneuve, S.; Pepin, V.; Rahayel, S.; Bertrand, J.A.; de Lorimier, M.; Rizk, A.; Desjardins, C.; Parenteau, S.; Beaucage, F.; Joncas, S.; et al. Mild cognitive impairment in moderate to severe COPD: a preliminary study. Chest.2012, 142(6), 1516-1523.

52. Prinzi, G.; Santoro, A.; Lamonaca, P.; Cardaci, V.; Fini, M.; Russo P. Cognitive Impairment in Chronic Obstructive Pulmonary Disease (COPD): Possible Utility of Marine Bioactive Compounds. Mar Drugs. 2018, 16(9). pii: E313.

53. Ising M, Depping AM, Siebertz A, Lucae S, Unschuld PG, Kloiber S, Horstmann S, Uhr M, Müller-Myhsok B, HolsboerF. Polymorphisms in the FKBP5 gene region modulate recovery from psychosocial stress in healthy controls. Eur J Neurosci. 2008 Jul;28(2):389-98. doi: 10.1111/j.1460-9568.2008.06332.x.

54. Di Carlo, A.; Baldereschi, M.; Lamassa, M.; Bovis, F.; Inzitari, M.; Solfrizzi, V.; Panza, F.; Galluzzo, L.; Scafato, E.; Inzitari, D. Italian Longitudinal Study on Aging Working Group. Daily Function as Predictor of Dementia in Cognitive Impairment, No Dementia (CIND) and Mild Cognitive Impairment (MCl): An 8-Year Follow-Up in the ILSA Study. J Alzheimers Dis. 2016;53(2), 505-15. 
55. Dantzer, R.; O'Connor, J.C.; Freund, G.G.; Johnson, R.W.; Kelley, K.W. From inflammation to sickness and depression: when the immune system subjugates the brain. Nat. Rev.Neurosci.2008, 9, 46e56.

56. Norwood, R.J. A review of etiologies of depression in COPD. Int. J. Chron. Obstruct. Pulmon. Dis. 2007,2, 485e91.

57. Dowlati,Y.; Herrmann, N.; Swardfager, W.; Liu, H.; Sham, L.; Reim, EK.; Lanctôt, K.L. A meta-analysis of cytokines in major depression. Biol. Psy-chiatry. 2010, 67, 446-457

58. Hiles, S. A.; Baker, A. L.; de Malmanche, T.; Attia, J. A meta-analysis of differences in IL-6 and IL-10 between people with and without depression: exploring the causes of heterogeneity. Brain Behav. Immun. 2012, 26, 1180-1188

59. Köhler, C.A.; Freitas, T.H.; Maes, M.; de Andrade, N.Q; Liu, C.S.; Fernandes, B.S.; Stubbs, B.; Solmi, M.; Veronese, N.; Herrmann, N.; et al. Peripheral cytokine and chemokine alterations in depression: a meta-analysis of 82 studies. Acta.Psychiatr. Scand. 2017, 135(5), 373-387.

60. Fan, N.; Luo, Y.; Ou, Y.; He, H. Altered serum levels of TNF- $\alpha$, IL-6, and IL-18 in depressive disorder patients. Hum Psychopharmacol. 2017, 32(4)

61. Rybka, J.;Korte, S.M.; Czajkowska-Malinowska M.; Wiese, M.; Kędziora-Kornatowska, K.; Kędziora, J. The links between chronic obstructive pulmonary disease and comorbid depressive symptoms: role of IL-2 and IFN- $\gamma$. ClinExp Med. 2016, 16(4), 493-502.

62. Du, Y.J.; Yang, C.J.; Li, B.; Wu, X.; Lu, Y.B.; Jin, H.L.; Cao, Y.X.; Sun, J.; Luo, Q.L.; Gong W.Y.; et al. Association of proinflammatory cytokines, cortisol and depression in patients with chronic obstructive pulmonary disease. Psycho neuroendocrinology. 2014,46,141-52.

63. Rao, S.; Yao, Y.; Ryan, J.;Li, T.; Wang, D.; Zheng, C.; Xu, Y.; Xu, Q. Common variants in FKBP5 gene and major depressive disorder (MDD) susceptibility: a comprehensive meta-analysis. Sci. Rep. 2016,6, 32687

64. Zobel, A.;Schuhmacher, A.; Jessen, F.;Höfels, S.; von Widdern, O.;Metten, M.; Pfeiffer, U.; Hanses, C.; Becker, T.;Rietschel, M.;Scheef, L.; et al. DNA sequence variants of the FKBP5 gene are associated with unipolar depression. Int. J.Neuropsychopharmacol.2010,13, 649-660

65. Lekman, M.; Laje, G.; Charney, D.; Rush, A.J.; Wilson, A.F.; Sorant, A.J.; Lipsky, R.; Wisniewski, S.R.; Manji, H.; McMahon, F.J.; Paddock, S. The FKBP5-gene in depression and treatment response-an association study in the Sequenced Treatment Alternatives to Relieve Depression (STAR*D) Cohort. Biol. Psychiatry. 2008,63, 1103-1110.

66. Zannas, A.S.; Binder, E.B. Gene-environment interactions at the FKBP5 locus: sensitive periods, mechanisms and pleiotropism. Genes Brain.Behav.2014,13, 25-37

67. Vermeer, H.; Hendriks-Stegeman, B.I.; van der Burg, B.; van Buul-Offers, S.C.; Jansen, M. Glucocorticoid-induced increase in lymphocytic FKBP51 messenger ribonucleic acid expression: a potential marker for glucocorticoid sensitivity, potency, and bioavailability. J.Clin.Endocrinol.Metab.2003, 88, 277-284.

68. Zhang, X.; Clark, A.F.;Yorio T. FK506-binding protein 51 regulates nuclear transport of the glucocorticoid receptor beta and glucocorticoid responsiveness. Investigative ophthalmol.\& visual science. 2008,49, 1037-1047

69. Zimmermann, P.; Brückl, T.; Nocon, A.; Pfister, H.; Binder, E.B.; Uhr, M.; Lieb, R.; Moffitt, T.E.; Caspi, A.; Holsboer, Ising, M. Interaction of FKBP5 gene variants and adverse life events in predicting depression onset: results from a 10-year prospective community study. Am. J. Psychiatry. 2011, 168, 1107-1116

70. Maltese, P.; Palma, L.; Sfara, C.; de Rocco, P.; Latiano, A.; Palmieri, O.; Corritore, G.; Annese, V.; Magnani M Glucocorticoid resistance in Crohn's disease and ulcerative colitis: an association study investigating GR and FKBP5 gene polymorphisms. Pharmacogenomics J. 2012, 12, 432-438.

71. Graydon, J.E.; Ross, E. Influence of symptoms, lung function, mood, and social support on level of functioning of patients with COPD. Res, Nurs, Health. 1995,18, 525-533

72. Vögele, C.; von Leupoldt, A. Mental disorders in chronic obstructive pulmonary disease (COPD). Respir. Med.2008, 102, 764-773. 
73. Mewes, R.; Rief, W.;Kenn, K.;Ried, J.;Stenzel, N. Psychological predictors for health-related quality of life and disability in persons with chronic obstructive pulmonary disease (COPD). Psychol. Health. 2016,31, 470-486.

74. Triest, F.; Franssen, F.M.E; Reynaert, N; Gaffron, S; Spruit, M.A; Janssen, D.J.A; Rutten, E.P.A; Wouters, E.F.M; Vanfleteren, L.E.G.W. Disease-Specific Comorbidity Clusters in COPD and Accelerated Aging. J.Clin. Med. 2019 Apr 14,8(4).

75. Saturni, S; Bellini, F; Braido, F.; Paggiaro, P.; Sanduzzi, A.; Scichilone, N.; Santus, P.A.; Morandi, L.; Papi, A. Randomized Controlled Trials and real life studies. Approaches and methodologies: a clinical point of view. Pulm. Pharmacol.Ther. 2014, 27(2), 129-138.

76. Viechtbauer, W.; Smits, L.; Kotz, D.; Budé, L.; Spigt, M.; Serroyen, J.; Crutzen, R. A simple formula for the calculation of sample size in pilot studies. J. Clin. Epidemiol.2015, 68, 1375-1379.

77. Cesario, A.; Auffray, C.; Agusti, A.; Apolone, G.; Balling, R.; Barbanti, P.; Bellia, A.; Boccia, S.; Bousquet, J.; Cardaci, V.; et al. A systems medicine clinical platform for understanding and managing non- communicable diseases. Curr. Pharm. Des.2014, 20, 5945-56

78. Magni. E.; Binetti, G.; Bianchetti, A.; Rozzini, R.; Trabucchi, M. Mini-Mental State Examination: a normative study in Italian elderly population. Eur J Neurol. 1996, 3(3), 198-202

79. Beck, A.T.; Steer, R.A.; Brown G.K. 1996. Manual for the Beck Depression Inventory-II. San Antonio, TX: Psychological Corporation.

80. American Psychiatric Association. Diagnostic and statistical manual of mental disorders. 4th ed. Washington: American Psychiatric Association. 1994

81. The Centre for Evidence-Based Medicine. Available online: https://www.cebm.net/ (accessed on May 2019).

82. Fava, G.A. Assessing depressive symptoms across cultures: Italian validation of the CES-D self-rating scale. J ClinPsychol.1983, 39, 249-251

83. Hitchcott, P.K.; Fastame, M.C.; Ferrai, J.; Penna, M.P. Psychological Well-Being in Italian Families: An Exploratory Approach to the Study of Mental Health Across the Adult Life Span in the Blue Zone. Eur J Psychol. 2017, 13(3),441-454.

84. Hertzog, C.; Van Alstine, J.; Usala, P.D. et al. Measurement properties of the Center for Epidemiological Studies Depression Scale (CES-D) in older populations. Psychol Assess1990, 2:64-72.

85. Dunstan, D.A.; Scott, N. Assigning Clinical Significance and Symptom Severity Using the Zung Scales: Levels of Misclassification Arising from Confusion between Index and Raw Scores. Depress Res Treat.2018,2018,9250972.

86. Brazier J. The SF-36 health survey questionnaire-a tool for economists. Health Econ. 1993,2,213-215.

87. Katz, S.; Downs, T.D.; Cash, H.R.; Grotz, R.C. Progress in development of the index of ADL. Gerontologist. 1970, 10, 20-30

88. Lawton, M.P.; Brody, E.M. Assessment of older people: Self-maintaining and instrumental activities of daily living. Gerontologist. 1969, 9, 179-186

89. Jones, P.W.; Quirk, F.H.; Baveystock, C.M.; Littlejohns, P. A self complete measure of health status for chronicairflow limitation. The St. George's Respiratory Questionnaire. Am. Rev. Respir. Dis.1992,145, 1321e7.

90. Carone, M.; Bertolotti, G.; Anchisi, F.; Zotti, A.M.; Donner, C.F.; Jones, P.W. Analysis of factors that characterize health impairment in patients with chronic respiratory failure. Quality of Life in Chronic Respiratory Failure Group. EurRespir J.1999,13(6),1293-1300.

91. Linn, B.S.; Linn, M.W.; Gurel, L. Cumulative illness rating scale. J. Am. Geriatr. Soc. 1968, 16, $622 \mathrm{e} 6$.

92. Miller, M.D.; Paradis, C.F.; Houck, P.R.; Mazumdar, S.; Stack, J.A.; Rifai, A.H. et al. Rating chronic medical illness burden in geropsychiatric practice and research: application of the Cumulative Illness Rating Scale. Psy-chiatry Res 1992, 41, 237e48

93. Carver, C. S. You want to measure coping but your protocol's too long: Consider the Brief COPE. Int J. of Behav. Med.1997, 4, 92-100. 